\title{
Research on Water Conservancy Project Based on Environmental Protection Concept
}

\author{
Jinlong Kang \\ Ningxia Qixing Canal Management Office, Yinchuan, Ningxia, China \\ renj1985@126.com
}

Keywords: Environmental protection concept, Water conservancy project, Existing problems, Effective measures

\begin{abstract}
With the deepening of urbanization, environmental problems have been a hot issue that people have been paying close attention to. As a basic project to maintain urban safety and provide good guarantee for urban water use, water conservancy project has a strong social public welfare nature and plays a positive role in promoting urban development. However, at this stage, with the construction and improvement of water conservancy projects, the scope is more and more extensive, which increases the difficulty in the comprehensive management, but also leads to some problems in the process of project construction, which affects the benign development of ecological environment. Therefore, the integration of environmental protection concept into water conservancy projects is conducive to promoting the mutual promotion and integration of ecological environment development and water conservancy project construction, so as to better play the positive role of water conservancy projects, strengthen its ability of flood control, power generation and continuous water supply.
\end{abstract}

\section{Introduction}

As one of the important national projects, water conservancy plays an important role in urban development. Water conservancy project can effectively maintain the ecological balance, avoid the harm of natural disasters, to a certain extent, ensure the health and safety of the people, at the same time, it has a profound significance for the development of water resources. At present, the concept of sustainable development and environmental protection has been implemented in all aspects of social development, including water conservancy projects. Integrating the concept into the construction of water conservancy projects can improve the deficiencies existing in the construction of water conservancy projects at this stage, and effectively play its positive role.

\section{Necessity of Integrating Environmental Protection Concept into Water Conservancy Project Construction}

Water conservancy project is different from other projects and has certain particularity. Its construction involves a wide range. It is not only necessary to carry out reasonable and detailed investigation and understanding of the surrounding environment and other conditions, but also to consider the traffic and transportation conditions, weather conditions, landform conditions and other contents of the area, so as to formulate a reasonable construction scheme. At the same time, it also leads to the water conservancy project vulnerable to a variety of factors, and may cause problems of construction quality and environmental safety. In addition, China has promulgated a number of laws, policies and systems for the construction of water conservancy projects to effectively restrict and promote water conservancy projects, and put forward that water conservancy projects are closely related to environmental protection.

Therefore, at this stage, promoting the integration of environmental protection concept and water conservancy projects is conducive to improving the existing engineering and environmental problems, and better promoting the harmonious development of urban construction and ecological 
environment. In addition, it can better play the various functions of water conservancy projects, improve their capacity of flood control, waterlogging prevention, water supply, power generation, ecological conservation, and coordinate the relationship between ecological environment, water resources and human beings, so as to better let the concept of environmental protection permeate the whole process of water conservancy project construction.

\section{Main Problems in Water Conservancy Project Construction Based on Environmental Protection Concept}

\subsection{The Awareness of Ecological and Environmental Protection is Relatively Weak}

In the process of social development at this stage, whether it is urban construction or residents' life, there are still some people who do not have a good sense of environmental protection, and more and more ignore the impact of environmental problems. Water conservancy projects can effectively solve the problem of water use, but if the construction is improper and environmental protection is not paid attention to, it will greatly damage the ecosystem, and then affect the ecological environment, exacerbated the ecological problems.

For example, due to the project construction, the land area and part of the wetland area are reduced, so that wetland plants lose their original habitat, resulting in the imbalance of ecological environment. This is because in the engineering design and construction stage, some leaders and managers do not have a good and comprehensive understanding of the ecological environment, and their environmental awareness is relatively weak, which leads to the blind consideration of the construction effect in the specific construction, without a detailed investigation and understanding of the surrounding environment and other issues. Only after the completion of the project can environmental problems be found. At the same time, the construction party pays too much attention to the economic benefits brought by the project, neglecting its social benefits and environmental protection value, thus causing a series of serious environmental problems.

\subsection{There is a Lack of Ecological and Environmental Protection Regulatory Policies}

With the gradual deepening of urbanization, China has also launched a series of policies, laws and systems for urban construction, and the environmental protection law has been constantly improved. However, in the actual construction process of water conservancy project at this stage, the relevant legal provisions and norms can not be effectively applied. At the same time, due to the difficulty of its implementation, the general applicability of the project construction is low, thus increasing the difficulty of environmental protection.

In addition, although the environmental protection system is relatively perfect, there is still a lack of certain standards and norms for the establishment of environmental protection supervision mechanism. As a result, some water conservancy construction units carry out non-standard construction operations due to poor supervision in the construction process, resulting in serious problems in project quality and greatly affecting the ecological environment. For the ecological supervision mechanism, there is no relevant reward and punishment system, so in order to consider more economic benefits, some management and construction personnel still ignore the importance of environmental protection on the basis of understanding the relevant specifications.

\subsection{The Investment of Environmental Protection Funds is Small}

For the construction of water conservancy projects, more energy and capital into the construction process is conducive to ensuring the construction quality and promoting the economic benefits of construction enterprises. However, for environmental protection, the lack of a certain amount of capital investment is not conducive to the healthy development of water conservancy projects in the long run, at the same time, it's not in line with the current concept of ecological environmental protection and the trend of sustainable development, aggravating the contradiction between ecological environment and project construction.

In addition, due to the small investment in environmental protection funds, the environmental 
protection infrastructure construction of the project is not comprehensive, which is not conducive to providing effective channels for environmental protection, and thus easy to develop into serious environmental protection problems.

\section{Effective Measures to Promote Water Conservancy Project Construction Based on the Concept of Environmental Protection}

\subsection{Strengthen the Construction of Ecological and Environmental Protection Awareness}

Water conservancy project is a major project constructed by human beings. Its purpose is to provide good water resources for human beings and protect the safety of the city and the majority of residents. It is of great significance for flood control and tuberculosis prevention, water storage and power generation. While enjoying the convenience brought by the project, we should also pay attention to strengthening the awareness of environmental protection, so as to better coordinate the close relationship between the ecosystem and human society. Therefore, it is necessary to put environmental protection awareness throughout the whole process of water conservancy project design and construction, and pay full attention to the significance of environmental protection.

In the design stage before construction, comprehensive consideration must be given to the construction site, environment, geographical conditions and other factors. On the basis of actual situation, relevant design specifications and environmental protection concepts should be followed to carry out scientific and reasonable project design. In addition, in the construction process, we should take perfect environmental protection measures rather than blindly consider the economic benefits and the construction process should greatly reduce the impact on the ecological environment.

\subsection{Establish a Sound Environmental Protection Assessment System}

In the current stage of water conservancy project construction process, due to poor supervision and imperfect environmental assessment, it is extremely easy to affect the ecosystem, which is not conducive to the healthy development of the ecological environment. Therefore, in view of this situation, the relevant departments must establish a sound environmental protection evaluation mechanism to enhance the rationality and authenticity of water conservancy project construction.

For the establishment of the system, it is necessary to ensure that it can scientifically and accurately evaluate the surrounding environment in the early stage, the middle stage and the later stage of construction, so as to make changes in project according to the evaluation and monitoring results, so as to realize the integration of project construction and environmental protection. In addition, in view of the problems in the environmental assessment, the relevant personnel can quickly grasp and carry out effective analysis, so as to improve the construction efficiency and quality of the water conservancy project, realize the protection of the ecological environment, reduce the negative impact of the project on the environment, and ensure its healthy development. Only by establishing a perfect and comprehensive environmental protection evaluation system can we promote the construction work towards the goal more truly and effectively, so as to realize the ecological development.

\subsection{Promote the Establishment of Environmental Compensation Mechanism}

As the water conservancy project construction and implementation process will have a certain impact on the environment, after the relevant units take a series of measures to minimize the impact of the project on the environment, certain compensation can be provided for the areas and individuals with environmental damage.

On the one hand, it can provide good financial support for the follow-up improvement of the environment, on the other hand, it can also encourage the construction of environmental protection and promote the establishment and improvement of environmental protection facilities. Therefore, the relevant departments must pay attention to this issue, make reasonable analysis according to the actual situation and environmental damage, establish a sound environmental compensation 
mechanism, so as to effectively solve the environmental damage and pollution problems. The relevant construction departments of the government should also fully consider the issue, increase the investment and support to ensure the effective establishment of environmental compensation mechanism. Only through this way, can we fundamentally promote the improvement of rectification ability of environmental damage areas, and provide financial support and guarantee for its benign development.

\subsection{Introduce Advanced Technology to Improve Environmental Protection Capability}

In order to better realize the mutual promotion and integration of ecological environment and water conservancy projects, in addition to the improvement in the construction and human-oriented aspects, we should also make full use of the products of the times and actively use advanced science and technology, so as to improve the environmental protection ability and efficiency.

Therefore, in the process of water conservancy project construction, remote sensing and geographic information technology can be actively used to effectively monitor and inspect the environment in this area, and more accurately analyze the environment. At the same time, the expert system and intelligent technology can also be used to reasonably evaluate the construction of water conservancy projects to find out the deficiencies in the construction process in time, so as to better improve the environment and project, promote the intelligent and scientific project construction, improve the construction efficiency and quality to a certain extent, and promote the benign ecosystem development.

In addition, in the era of rapid development of economy, science and technology, we should also pay attention to the introduction of new technologies. By actively introducing new technologies and measures, we can greatly improve the ability of environmental protection, truly play the role of water conservancy projects, improve the quality of water resources for people, and promote the healthy development of the ecosystem.

\section{Conclusion}

In a word, in the current environment of rapid economic development and gradual improvement of people's living standards, the demand for water and the quality of water resources is becoming higher and higher. In order to better promote the construction of water conservancy projects in China, so as to meet the current huge water demand and provide safe water environment for urban residents, we must pay attention to its sustainable development. Therefore, fully integrating the concept of environmental protection with the construction of the projects can minimize the impact on the environment during the construction of the projects, prevent and control the problems of pollution and damage to the ecological environment, promote its sustainable development, and then make the city operate well and provide a solid guarantee for the lives of the majority of residents.

\section{References}

[1] Xu Liezhong, Ren Jiafei. Application of Ecological Concept in Water Conservancy Design. Pearl River Water Transport, no.12, pp.93-94, 2020.

[2] Wang Jiahao. Research on Water Conservancy Engineering Design Based on Ecological Concept. Construction Engineering Technology and Design, no.12, pp.3443, 2018.

[3] Shen Guangqiang. Study on Ecological Concept of River Regulation Planning and Design. Construction Engineering Technology and Design, no.14, pp.3006, 2017.

[4] Zhang Shihao. Research Method of Hydraulic Engineering Design Based on the Concept of Ecological Civilization Development. Hydropower Economy, vol.000, no.006, pp.170, 2018. 